\title{
The influence of alcohol content variation in UK packaged beers on the uncertainty of calculations using the Widmark equation
}

\author{
Peter D. Maskell \\ Calum Holmes \\ Margaux Huismann \\ Struan Reid \\ Martin Carr \\ Benjamin J. Jones \\ Dawn L. Maskell \\ PII: \\ S1355-0306(18)30001-7 \\ DOI: \\ doi:10.1016/j.scijus.2018.03.003 \\ Reference: \\ SCIJUS 721 \\ To appear in: \\ Science \& Justice \\ Received date: \\ 4 January 2018 \\ Revised date: \\ 19 February 2018 \\ Accepted date: \\ 4 March 2018
}

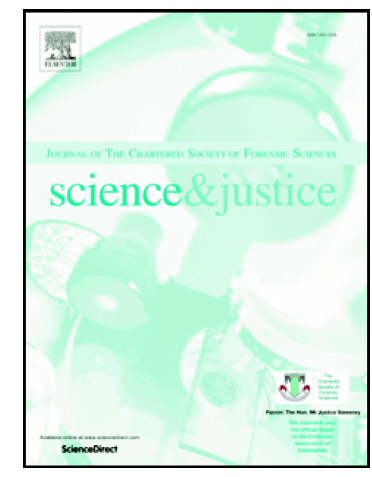

Please cite this article as: Peter D. Maskell, Calum Holmes, Margaux Huismann, Struan Reid, Martin Carr, Benjamin J. Jones, Dawn L. Maskell, The influence of alcohol content variation in UK packaged beers on the uncertainty of calculations using the Widmark equation. The address for the corresponding author was captured as affiliation for all authors. Please check if appropriate. Scijus(2018), doi:10.1016/j.scijus.2018.03.003

This is a PDF file of an unedited manuscript that has been accepted for publication. As a service to our customers we are providing this early version of the manuscript. The manuscript will undergo copyediting, typesetting, and review of the resulting proof before it is published in its final form. Please note that during the production process errors may be discovered which could affect the content, and all legal disclaimers that apply to the journal pertain.

This is the accepted manuscript (C) 2018, Elsevier Licensed under the Creative Commons Attribution-NonCommercial-NoDerivatives 4.0 International (CC BY-NC-ND 4.0) http://creativecommons.org/licenses/by-nc-nd/4.0/ 
The influence of alcohol content variation in UK packaged beers on the uncertainty of calculations using the Widmark Equation.

Peter D Maskell ${ }^{1^{*}}$, Calum Holmes ${ }^{2}$, Margaux Huismann ${ }^{2}$ Struan Reid $^{2}$, Martin Carr $^{3}$, Benjamin J Jones ${ }^{1}$, Dawn L Maskell ${ }^{2}$

${ }^{1}$ School of Science, Engineering and Technology, Abertay University. Dundee. Scotland. UK.

${ }^{2}$ International Centre for Brewing and Distilling, School of Engineering and Physical Sciences. Heriot-Watt University. Riccarton. Edinburgh. UK.

${ }^{3}$ School of Applied Sciences, University of Huddersfield. Huddersfield. UK

*Author to whom correspondence should be addressed. 


\begin{abstract}
It is common for forensic practitioners to calculate an individual's likely blood alcohol concentration following the consumption of alcoholic beverage(s) for legal purposes, such as in driving under the influence (DUI) cases. It is important in these cases to be able to give the uncertainty of measurement on any calculated result, for this reason uncertainty data for the variables used for any calculation are required. In order to determine the uncertainty associated with the alcohol concentration of beer in the UK the alcohol concentration $(\% \mathrm{v} / \mathrm{v})$ of 218 packaged beers (112 with an alcohol concentration of $\leq 5.5 \% \mathrm{v} / \mathrm{v}$ and 106 with an alcohol concentration of $>5.5$ $\% \mathrm{v} / \mathrm{v}$ ) were tested using an industry standard near infra-red (NIR) analyser. The range of labelled beer alcohol by volume (ABV's) tested was $3.4 \% \mathrm{v} / \mathrm{v}-14 \% \mathrm{v} / \mathrm{v}$. The beers were obtained from a range of outlets throughout the UK over a period of 12 months. The root mean square error (RMSE) was found to be $\pm 0.43 \% \mathrm{v} / \mathrm{v}$ (beers with declared $\% A B V$ of $\leq 5.5 \% \mathrm{v} / \mathrm{v}$ ) and $\pm 0.53 \% \mathrm{v} / \mathrm{v}$ (beers with declared $\% A B V$ of $>5.5 \% \mathrm{v} / \mathrm{v}$ ) the RMSE for all beers was $\pm 0.48 \% \mathrm{v} / \mathrm{v}$. The standard deviation from the declared \%ABV is larger than those previously utilised for uncertainty calculations and illustrates the importance of appropriate experimental data for use in the determination of uncertainty in forensic calculations.
\end{abstract}

Keywords: Alcohol technical defence; Blood alcohol calculation; Alcohol by volume; Beer; Uncertainty; Driving Under the Influence. 


\section{Introduction}

As the pharmacokinetics of alcohol are well understood, it is permissible in law to utilise the Widmark equation (equation 1) to determine the blood alcohol concentration at a specific time if a blood (or alternative) sample is not available for that time point.

$C_{t}=\frac{v z d}{r M}-\beta t$

$\mathrm{C}_{\mathrm{t}}=$ blood alcohol (ethanol) concentration at time $\mathrm{t}(\mathrm{mg} / 100 \mathrm{ml})$

$\mathrm{v}=$ volume of alcoholic beverage consumed $(\mathrm{ml})$

$z=$ strength of alcohol beverage $(\% \mathrm{v} / \mathrm{v})$

$\mathrm{d}=$ density of ethanol $(\mathrm{g} / \mathrm{ml})$

$r=$ the volume of distribution $\left(V_{d}\right)$ of ethanol in an individual (unitless)

$M=$ mass of the subject $(\mathrm{kg})$

$\beta=$ alcohol elimination rate $(\mathrm{mg} / 100 \mathrm{ml} / \mathrm{h})$

$\mathrm{t}=$ time the drinking began $(\mathrm{h})$

Recent guidance by both the UK Forensic Science Regulator [1] and the National Academy of Sciences (NAS) report [2] on strengthening forensic science in the USA have reiterated the importance of including the uncertainty that may be associated with any forensic methods that are utilised. For this reason it is therefore important to determine the associated uncertainties for each of the parameters in the Widmark equation to give the best possible uncertainty of any Widmark based calculations.

Beer is one of the most popular drinks in the UK [3] and is also the most likely to be drunk in "binge drinking" sessions [3]. Due to the lower alcohol concentration of beer compared to wine or sprits (such as whisk(e)y) differences in the actual alcohol content of beer compared to the labelled alcohol content could exhibit greater levels of uncertainty. Previous experimental data from the USA demonstrated that the standard deviation (SD) of the actual alcohol content of packaged beer compared to the labelled alcohol content was $\pm 0.40 \% \mathrm{v} / \mathrm{v}(\mathrm{n}=85)$ [4]. Maskell and colleagues have previously suggested that, in the UK, based on legal statute and \%ABV measurement accuracy data, that a SD of $\pm 0.14 \% \mathrm{v} / \mathrm{v}$ (for beers $\leq 5.5 \% \mathrm{v} / \mathrm{v}$ ) and \pm $0.34 \% \mathrm{v} / \mathrm{v}$ (for beers $>5.5 \% \mathrm{v} / \mathrm{v}$ ) should be used for uncertainty calculations [5]. However, there have been no published experimental studies comparing the actual alcohol content of beer to labelled alcohol content in the UK. A study in the UK that determined experimental rather than theoretical alcohol concentration accuracy data for uncertainty of measurement calculations would be useful to give more reliable 
data for determining the overall uncertainty for alcohol calculations using the Widmark equation.

The aim of this study was to determine the SD (and percent coefficient of variation $(\% \mathrm{CV}))$ of the labelled \%ABV on packaged, UK brewed beer to provide experimentally derived \%ABV data for uncertainty calculations when using the Widmark equation. The influence of the experimentally derived uncertainty of alcohol concentration on the uncertainty Widmark calculations of the maximum blood alcohol concentration is also shown.

\section{Methodology}

\subsection{Sample Selection}

In order to determine the uncertainty (standard deviation (SD) and percent coefficient of variance $(\% \mathrm{CV}))$ of the labelled \%ABV of packaged beer (bottles and can) 218 different beers brewed in the UK were sampled (107 $\leq 5.5 \%$ alcohol by volume $(\% \mathrm{ABV} ; \% \mathrm{v} / \mathrm{v})$ and $106>5.5 \% \mathrm{ABV})$. The samples were divided into these two groupings as European Union legislation (enacted by UK legislation [6]) allows a variation from the labelled content of $\pm 0.5 \% \mathrm{v} / \mathrm{v}$ (for beers $\leq 5.5 \% \mathrm{v} / \mathrm{v}$ ) and \pm 1.0 $\% \mathrm{v} / \mathrm{v}$ (for beers $>5.5 \% \mathrm{v} / \mathrm{v}$ ) [7]. The beers were purchased in different Counties of England and Scotland (Angus, Berkshire, Fife, Lancashire, Midlothian, Orkney and Yorkshire) between October 2016 and October 2017.

\subsection{Sample Analysis}

Upon opening the beer, $50 \mathrm{ml}$ was immediately decanted into a $50 \mathrm{ml} \mathrm{Falcon}^{\mathrm{TM}}$ conical centrifuge tube (Fisher Scientific, Loughborough, UK) and stored in a refrigerator $\left(\sim 4-10{ }^{\circ} \mathrm{C}\right)$ for no more than 7 days until analysis. The \%ABV of the beer was measured in duplicate using two $20 \mathrm{ml}$ aliquot using an Anton Parr DMA 4500M density meter, fitted with an Alcolyzer Beer ME module (Anton Parr, St Albans, UK). Each sample was measured in duplicate and the mean used for further calculation. According to the manufacturer's data, this instrument has a repeatability (standard deviation (SD)) of $\pm 0.01 \% \mathrm{v} / \mathrm{v}$. This analytical method is approved by MEBAK (Central European Commission for Brewing Analysis) for measurement of $\% A B V[8]$.

\subsection{Data Analysis}

Analysis of the data was performed with Excel 2016 (Microsoft, Redmond, WA, USA). The root mean square error (RMSE) was calculated using equation (2).

$R M S E=\sqrt{\frac{\sum_{i=1}^{n}(P-O)^{2}}{n}}$

$R M S E=$ Root mean square error 
$n=$ number of predictions

$P=$ experimentally determined \%ABV $(\% \mathrm{v} / \mathrm{v})$

$O=$ labelled \%ABV $(\% \mathrm{v} / \mathrm{v})$

The RMSE represents the sample standard deviation of the differences between the predicted (experimentally determined \%ABV) and the observed (labelled \%ABV) values.

Histogram analysis for Gaussian distribution was performed with SPSS Statistics v23.0.0.3 (IBM, Armock NY, USA). The contribution of each variable to the overall uncertainty of measurement for blood alcohol concentration was calculated using GUM Workbench EDU Software v2.4.1.384 (Metrodata GmbH, www.metrodata.de) using the variables from Table 2 and equation 3.

$C_{o}=\frac{100 v z d}{r M}$

$\mathrm{C}_{0}=$ the maximum theoretical $\mathrm{BAC}$ at the time the ethanol dose was administered $(\mathrm{mg} / 100 \mathrm{ml})$ assuming complete and instantaneous absorption.

\section{Results and Discussion}

In order to determine the uncertainty of the declared alcohol concentration in packaged (canned and bottled) beer, the alcohol content of 218 different beers was measured. As the uncertainty in the EU (and thus the UK) is allowed to be greater for beers with an alcohol content of $\geq 5.5 \% \mathrm{v} / \mathrm{v}$, the RMSE for both groups $(<5.5$ $\% \mathrm{v} / \mathrm{v}, \geq 5.5 \% \mathrm{v} / \mathrm{v}$ ) was determined. As can be seen in figures $1 \mathrm{~A}$ and $1 \mathrm{~B}$, the measured alcohol concentrations were all normally distributed. This allowed the RMSE of both groups to be calculated, with the RMSE used in place of standard deviation as it was comparing the predicted (labelled) alcohol content to the observed (experimentally determined) alcohol content for uncertainty calculations. The RMSE for beers of $<5.5 \% \mathrm{v} / \mathrm{v}$ was $\pm 0.43 \% \mathrm{v} / \mathrm{v}$ and for beers $\geq 5.5 \% \mathrm{v} / \mathrm{v}$ was \pm $0.53 \% \mathrm{v} / \mathrm{v}$. The RMSE for all beers was $\pm 0.48 \% \mathrm{v} / \mathrm{v}$. The calculation of the uncertainty of $\mathrm{C}_{0}$ using the Widmark equation has been detailed by both Searle [9] and Gullberg [10]. The simplest method of calculation of the uncertainty involves the use of \%CV of the relevant parameter, rather than the standard deviation. The \%CV has been provided for $1-3 \sigma(68-99 \% \mathrm{Cl})$ and is shown in Figure 2 and Table 1, as different confidence intervals may be required depending on the type of court case. For example, $68 \%(1 \sigma)$ in the case of civil trial where the standard of proof only needs to on the "balance of probability" rather than that of "beyond reasonable doubt" where $2 \sigma(95 \% \mathrm{Cl})$ or $3 \sigma(99.7 \% \mathrm{Cl})$ would be more appropriate. The discontinuity of \%CV observed in Figure 2 and Table 1 is due to the change in the legally allowable variation in \%ABV between beverages of $<5.5 \% \mathrm{v} / \mathrm{v}$ and $\geq 5.5 \% \mathrm{v} / \mathrm{v}$. 
In our previous work [5], we demonstrated that a SD of $\pm 0.14 \% \mathrm{v} / \mathrm{v}$ (for beers $\leq 5.5$ $\% \mathrm{v} / \mathrm{v}$ ) and $\pm 0.34 \% \mathrm{v} / \mathrm{v}$ (for beers $>5.5 \% \mathrm{v} / \mathrm{v}$ ) was appropriate based on statutory variation and measurement uncertainty. However, this is lower than the experimentally determined values in the present study, which are similar to those found from experimental studies in the USA where the SD was $\pm 0.40 \% \mathrm{v} / \mathrm{v}$ [4]. The larger variations observed in the experimental studies in this work may be a reflection of the number of "craft" breweries and beers utilised in this study. Unlike in the USA [11] there is no definition of what constitutes a 'craft' brewery in the UK. For the purposes of this study they are assumed to be small, independent businesses. Often due to limited size and turn over, investment in specialist equipment such as the Anton-Parr Alcolyser (used in this study) may not be a priority. It is permissible in UK legislation for brewers to use hydrometers to determine \%ABV which are not as accurate as other methods such as the distillation method of determining \%ABV [12]. It is proposed that this inherent variability in the different methodologies utilised may account for the larger than expected variabilities. With revised \%CV for the declared alcohol concentrations, it is important to determine the influence that this may have on both the error when calculating $C_{0}$ and also to provide revised estimates for the proportion of the alcohol concentration to the overall uncertainty. In order to do this we used example data of an individual (previously used by Gullberg [10], Maskell et al. [5], and Searle [9]) to allow a comparison of this work with previous uncertainty calculations. It is important to note that the final uncertainty calculated for $\mathrm{C}_{0}$ would depend on the inputted variables for an individual and that best practice is to determine $r$ using anthropometric equations (such as Watson et al.,[13], Forrest ([14] or Seidl et al., [15] rather than using a fixed value for $r$.

Previously determined variables used were volume of distribution of ethanol $\left(\mathrm{V}_{\mathrm{d}}\right)$, sex, weight, volume of drink and alcohol density (Table 2) in order to calculate the $\mathrm{C}_{\circ}$ for a range of beer alcohol concentrations $(3.4 \% \mathrm{v} / \mathrm{v}-12.4 \% \mathrm{v} / \mathrm{v})$. As can be seen from Table 3, the \%CV of the calculated $C_{0}$ decreased from $16 \%$ to $10 \%$ with increasing alcohol. The proportional contribution of the alcohol concentration to the overall uncertainty error, again, reduces with increasing alcohol concentration (64.1 $\%$ to $17.0 \%)$. With higher alcohol concentration beverages (such as wine $(\sim 12-15$ $\% \mathrm{v} / \mathrm{v}$ ) or whisk(e)y $\sim 45 \% \mathrm{v} / \mathrm{v})$ ) the overall contribution would be much lower, to both the error in $\mathrm{C}_{0}$ and also as a proportion of the total error. Previous studies have already determined that the largest contributor to the overall uncertainty in Widmark calculations is the alcohol elimination rate and the subject's volume of distribution for ethanol $[5,9,10]$ (in this study $34.1 \%$ to $78.9 \%$ of the total uncertainty).

The increased variation of actual alcohol concentration from the declared alcohol concentration are larger than those previously utilised for uncertainty calculations. This illustrates the importance of using appropriate experimental data for use in the determination of uncertainty in forensic calculations.

\section{Acknowledgements}


The authors would like to thank Kevin Farrugia, Matt Bivins, Simon Moss, Ryan Milne, Monica Arso Civil, Izzy Langley, Steve Balfour, Chris McKnight, Hannah Wood, Kathryn White and the Students of the International Centre for Brewing and Distilling for drinking beer for the purposes of science.

\section{Funding}

This study was funded by the authors and the drinkers of beer for science. 


\section{References}

[1] Forensic Science Regulator, FSR-G-200 Expert report guidance, 2017. https://www.gov.uk/government/publications/expert-report-content (accessed October 27, 2017).

[2] National Academy of Sciences. Strengthening Forensic Science in the United States: A Path Forward, 2009. doi:10.1016/0379-0738(86)90074-5.

[3] Office of National Statistics, Adult drinking habits in Great Britain - Office for National Statistics, 2017.

https://www.ons.gov.uk/peoplepopulationandcommunity/healthandsocialcare/d rugusealcoholandsmoking/bulletins/opinionsandlifestylesurveyadultdrinking hab itsingreatbritain/2005to2016 (accessed November 22, 2017).

[4] B.K. Logan, G.A. Case, S. Distefano, Alcohol content of beer and malt beverages: forensic consideration., J. Forensic Sci. 44 (1999) 1292-1295.

[5] P.D. Maskell, R. Alex Speers, D.L. Maskell, Improving uncertainty in Widmark equation calculations: Alcohol volume, strength and density, Sci. Justice. (2017). doi:10.1016/j.scijus.2017.05.006.

[6] H. Government, THE FOOD LABELLING REGULATIONS 1996 :, (1996) 1-34. http:/www.legislation.gov.uk/uksi/1996/1499/contents/made (accessed December 4, 2017).

[7] EU regulation 1169/2011, 2011. http://eur-lex.europa.eu/legalcontent/EN/ALL/?uri=CELEX:32011R1169 (accessed October 30, 2017).

[8] Alcolyzer ME Measuring Module, (n.d.). https://www.antonpaar.com/?elD=documentsDownload\&document $=55783 \& \mathrm{~L}=38$ (accessed October 30, 2017).

[9] J. Searle, Alcohol calculations and their uncertainty, Med. Sci. Law. 55 (2015) 58-64. doi:10.1177/0025802414524385.

[10] R.G. Gullberg, Estimating the uncertainty associated with Widmark's equation as commonly applied in forensic toxicology, Forensic Sci. Int. 172 (2007) 3339. doi:10.1016/j.forsciint.2006.11.010.

[11] Brewers Association, CRAFT BREWER DEFINED, (2017). https://www.brewersassociation.org/statistics/craft-brewer-defined/ (accessed December 4, 2017).

[12] HM Revenue \& Customs, Excise Notice 226: Beer Duty - GOV.UK, 2017. https://www.gov.uk/government/publications/excise-notice-226-beer-duty (accessed December 4, 2017). 
[13] P.E. Watson, I.D. Watson, R.D. Batt, Prediction of blood alcohol concentrations in human subjects. Updating the Widmark equation, J. Stud. Alcohol. 42 (1981).

[14] A.R.W. Forrest, The estimation of Widmark's factor, J. Forensic Sci. Soc. 26 (1986).

[15] S. Seidl, U. Jensen, A. Alt, The calculation of blood ethanol concentrations in males and females, Int. J. Legal Med. 114 (2000). doi:10.1007/s004140000154. 
Figure 1A: Histogram of the residuals of the $112 \mathrm{UK}$ beers with a declared \%ABV of $\leq 5.5 \%$ showing normal distribution.

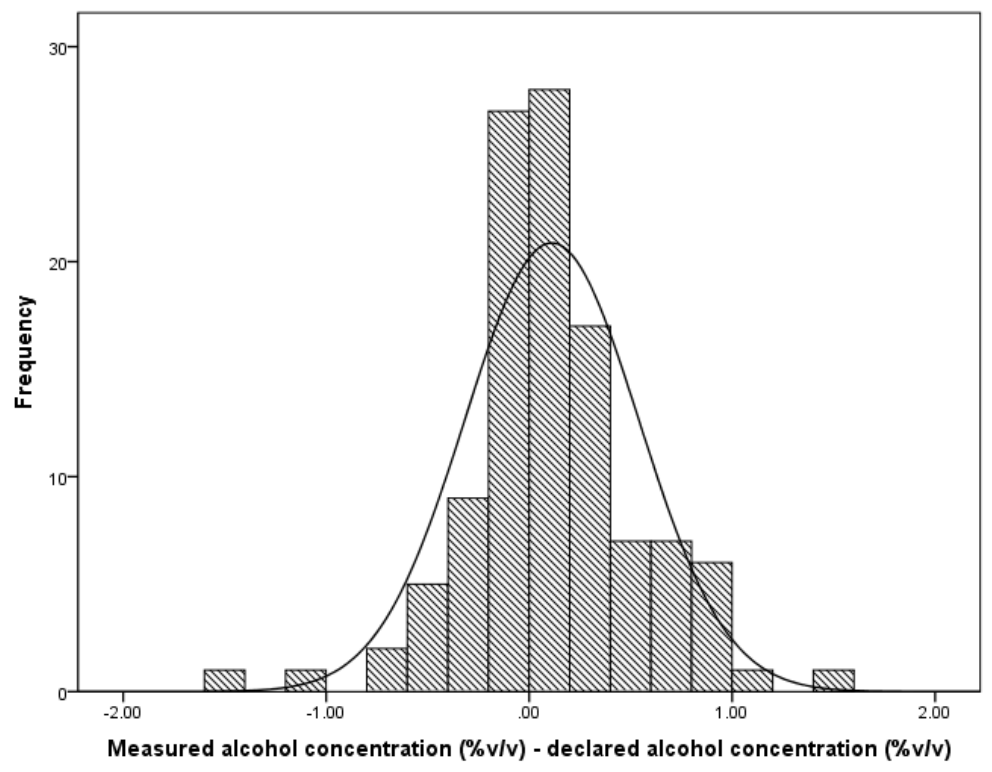

Figure 1B: Histogram of the residuals of the $106 \mathrm{UK}$ beers with a declared \%ABV of $>5.5 \%$ showing normal distribution.

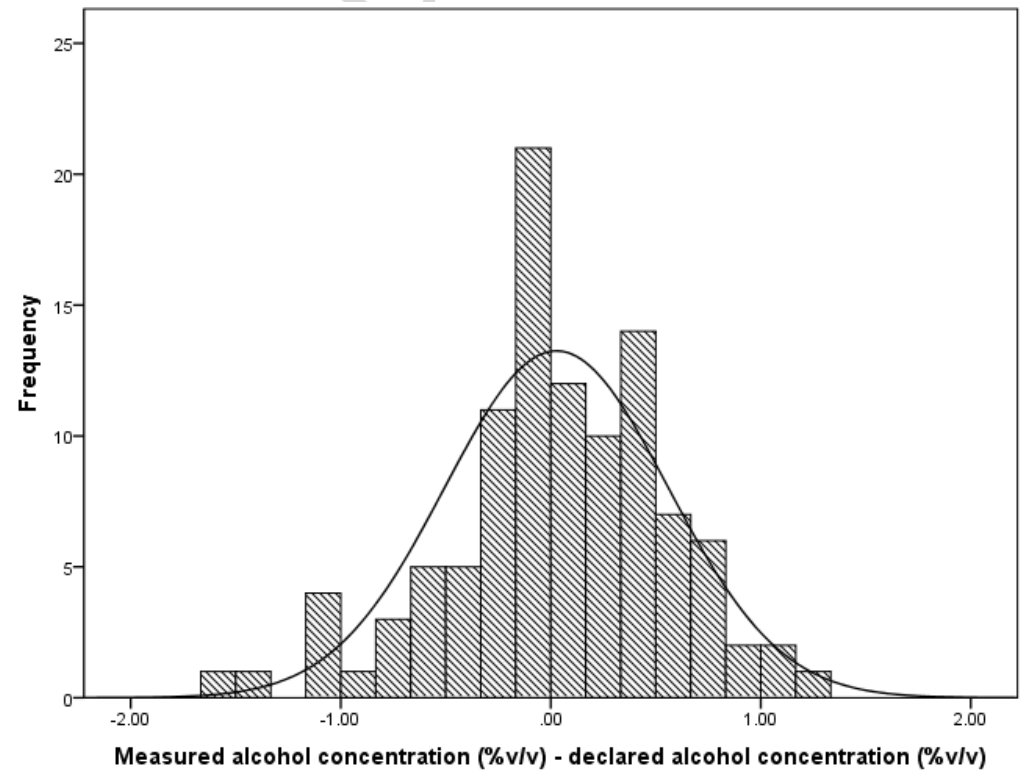


Figure 2: The \%CV that should be utilised for uncertainty calculations when the $\% A B V$ of the beer is known. The data is given for $1 \sigma(68 \% \mathrm{Cl}), 2 \sigma(95 \% \mathrm{Cl})$ and $3 \sigma$ $(99.7 \% \mathrm{Cl})$.

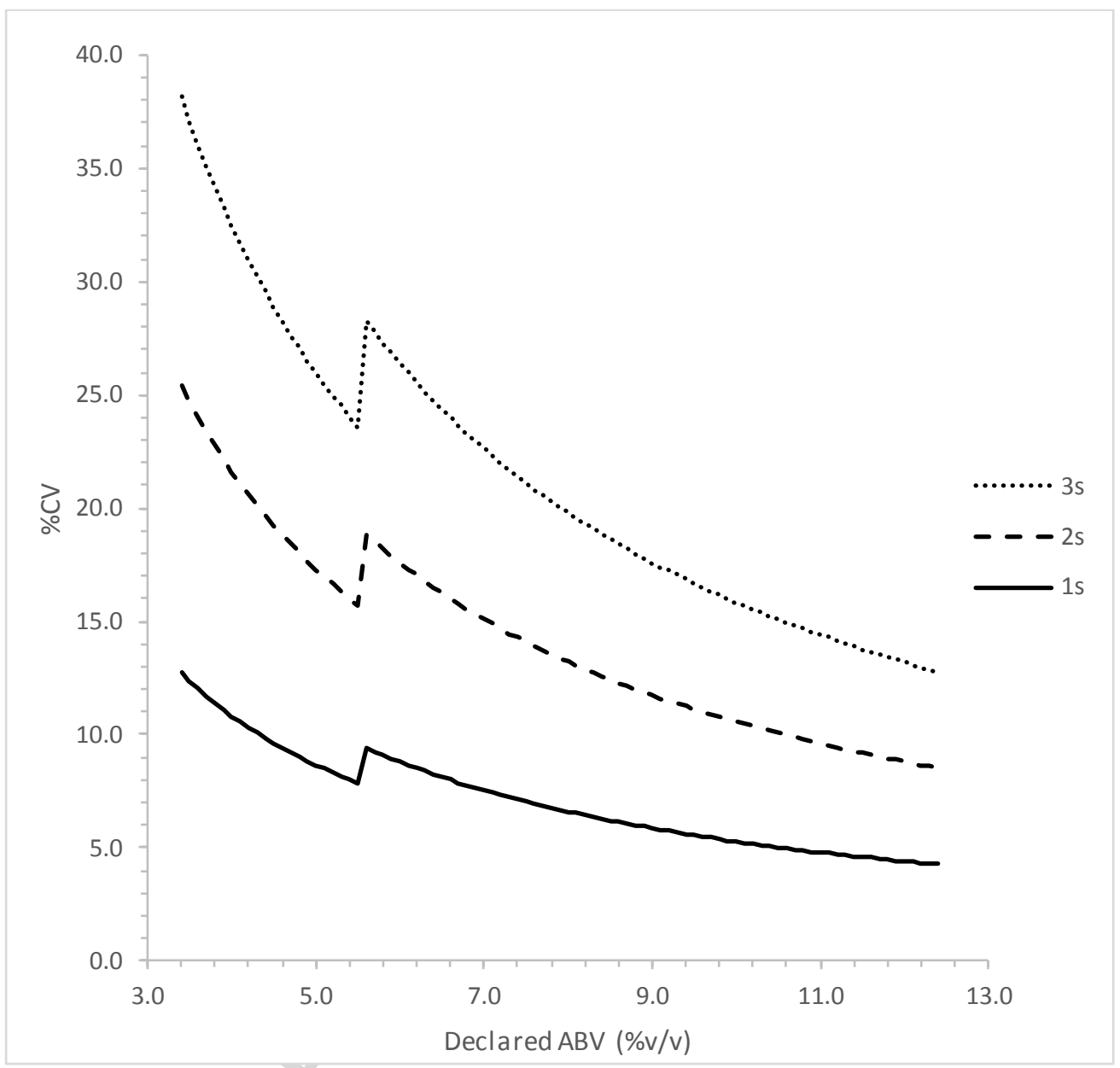


Table 1: The \%CV that should be utilised for uncertainty calculations when the $\% A B V$ of the beer is known. The data is given for $1 \sigma(68 \% \mathrm{Cl}), 2 \sigma(95 \% \mathrm{Cl})$ and $3 \sigma$ $(99.7 \% \mathrm{Cl})$.

\begin{tabular}{|c|c|c|c|}
\hline \multirow{2}{*}{$\% A B V$} & \multicolumn{3}{|c|}{ \%CV } \\
\hline & $1 \sigma$ & $2 \sigma$ & $3 \sigma$ \\
\hline 3.4 & 12.7 & 25.4 & 38.2 \\
\hline 3.5 & 12.4 & 24.7 & 37.1 \\
\hline 3.6 & 12.0 & 24.0 & 36.1 \\
\hline 3.7 & 11.7 & 23.4 & 35.1 \\
\hline 3.8 & 11.4 & 22.8 & 34.2 \\
\hline 3.9 & 11.1 & 22.2 & 33.3 \\
\hline 4.0 & 10.8 & 21.6 & 32.4 \\
\hline 4.1 & 10.6 & 21.1 & 31.7 \\
\hline 4.2 & 10.3 & 20.6 & 30.9 \\
\hline 4.3 & 10.1 & 20.1 & 30.2 \\
\hline 4.4 & 9.8 & 19.7 & 29.5 \\
\hline 4.5 & 9.6 & 19.2 & 28.8 \\
\hline 4.6 & 9.4 & 18.8 & 28.2 \\
\hline 4.7 & 9.2 & 18.4 & 27.6 \\
\hline 4.8 & 9.0 & 18.0 & 27.0 \\
\hline 4.9 & 8.8 & 17.7 & 26.5 \\
\hline 5.0 & 8.7 & 17.3 & 26.0 \\
\hline 5.1 & 8.5 & 17.0 & 25.4 \\
\hline 5.2 & 8.3 & 16.6 & 25.0 \\
\hline 5.3 & 8.2 & 16.3 & 24.5 \\
\hline 5.4 & 8.0 & 16.0 & 24.0 \\
\hline 5.5 & 7.9 & 15.7 & 23.6 \\
\hline 5.6 & 9.4 & 18.9 & 28.3 \\
\hline 5.7 & 9.3 & 18.5 & 27.8 \\
\hline 5.8 & 9.1 & 18.2 & 27.3 \\
\hline 5.9 & 8.9 & 17.9 & 26.8 \\
\hline 6.0 & 8.8 & 17.6 & 26.4 \\
\hline 6.1 & 8.7 & 17.3 & 26.0 \\
\hline 6.2 & 8.5 & 17.0 & 25.5 \\
\hline 6.3 & 8.4 & 16.8 & 25.1 \\
\hline 6.4 & 8.3 & 16.5 & 24.8 \\
\hline 6.5 & 8.1 & 16.2 & 24.4 \\
\hline 6.6 & 8.0 & 16.0 & 24.0 \\
\hline 6.7 & 7.9 & 15.8 & 23.6 \\
\hline 6.8 & 7.8 & 15.5 & 23.3 \\
\hline 6.9 & 7.7 & 15.3 & 23.0 \\
\hline 7.0 & 7.5 & 15.1 & 22.6 \\
\hline
\end{tabular}




\begin{tabular}{|c|c|c|c|}
\hline 7.1 & 7.4 & 14.9 & 22.3 \\
\hline 7.2 & 7.3 & 14.7 & 22.0 \\
\hline 7.3 & 7.2 & 14.5 & 21.7 \\
\hline 7.4 & 7.1 & 14.3 & 21.4 \\
\hline 7.5 & 7.0 & 14.1 & 21.1 \\
\hline 7.6 & 6.9 & 13.9 & 20.8 \\
\hline 7.7 & 6.9 & 13.7 & 20.6 \\
\hline 7.8 & 6.8 & 13.5 & 20.3 \\
\hline 7.9 & 6.7 & 13.4 & 20.1 \\
\hline 8.0 & 6.6 & 13.2 & 19.8 \\
\hline 8.1 & 6.5 & 13.0 & 19.6 \\
\hline 8.2 & 9.1 & 18.2 & 27.3 \\
\hline 8.3 & 8.9 & 17.9 & 26.8 \\
\hline 8.4 & 8.8 & 17.6 & 26.4 \\
\hline 8.5 & 8.7 & 17.3 & 26.0 \\
\hline 8.6 & 8.5 & 17.0 & 25.5 \\
\hline 8.7 & 8.4 & 16.8 & 25.1 \\
\hline 8.8 & 8.3 & 16.5 & 24.8 \\
\hline 8.9 & 8.1 & 16.2 & 24.4 \\
\hline 9.0 & 8.0 & 16.0 & 24.0 \\
\hline 9.1 & 7.9 & 15.8 & 23.6 \\
\hline 9.2 & 7.8 & 15.5 & 23.3 \\
\hline 9.3 & 7.7 & 15.3 & 23.0 \\
\hline 9.4 & & 15.1 & 22.6 \\
\hline 9.5 & 7.4 & 14.9 & 22.3 \\
\hline 9.6 & & 14.7 & 22.0 \\
\hline 9.7 & 7.2 & 14.5 & 21.7 \\
\hline 9.8 & 7.1 & 14.3 & 21.4 \\
\hline 9.9 & 7.0 & 14.1 & 21.1 \\
\hline 10.0 & 6.9 & 13.9 & 20.8 \\
\hline 10.1 & 6.9 & 13.7 & 20.6 \\
\hline 10.2 & 6.8 & 13.5 & 20.3 \\
\hline 10.3 & 6.7 & 13.4 & 20.1 \\
\hline 10.4 & 6.6 & 13.2 & 19.8 \\
\hline 10.5 & 6.5 & 13.0 & 19.6 \\
\hline 10.6 & 5.0 & 10.0 & 14.9 \\
\hline 10.7 & 4.9 & 9.9 & 14.8 \\
\hline 10.8 & 4.9 & 9.8 & 14.7 \\
\hline 10.9 & 4.8 & 9.7 & 14.5 \\
\hline 11.0 & 4.8 & 9.6 & 14.4 \\
\hline 11.1 & 4.8 & 9.5 & 14.3 \\
\hline 11.2 & 4.7 & 9.4 & 14.1 \\
\hline 11.3 & 4.7 & 9.3 & 14.0 \\
\hline 11.4 & 4.6 & 9.3 & 13.9 \\
\hline
\end{tabular}




\begin{tabular}{|l|lll|}
11.5 & 4.6 & 9.2 & 13.8 \\
11.6 & 4.6 & 9.1 & 13.7 \\
11.7 & 4.5 & 9.0 & 13.5 \\
11.8 & 4.5 & 8.9 & 13.4 \\
11.9 & 4.4 & 8.9 & 13.3 \\
12.0 & 4.4 & 8.8 & 13.2 \\
12.1 & 4.4 & 8.7 & 13.1 \\
12.2 & 4.3 & 8.7 & 13.0 \\
12.3 & 4.3 & 8.6 & 12.9 \\
12.4 & 4.3 & 8.5 & 12.8 \\
\hline
\end{tabular}


Table 2: Example variable values from a fictitious individual (and associated uncertainties) used to estimate the blood alcohol concentration calculated with the Widmark equation.

\begin{tabular}{|c|c|c|c|}
\hline Variable & Value & Uncertainty (S.D.) & \% CV \\
\hline Sex & Male & 1.4 & $2.0^{\mathrm{a}}$ \\
\hline Weight (kg) & $70^{\mathrm{a}}$ & 0.064 & $9.2^{\mathrm{a}}$ \\
\hline $\begin{array}{c}\mathbf{V}_{\mathbf{d}} \text { of ethanol (r; } \\
\mathbf{l} / \mathbf{k g})\end{array}$ & $0.7^{\mathrm{a}}$ & $3.81^{\mathrm{b}}$ & $0.67^{\mathrm{b}}$ \\
\hline $\begin{array}{c}\text { Volume of Drink } \\
(\mathbf{v} ; \mathbf{m l})\end{array}$ & $568(1 \mathrm{UK}$ pint) & $5.9 \times 10^{-4} \mathrm{~b}$ & $0.06^{\mathrm{b}}$ \\
\hline $\begin{array}{c}\text { Alcohol Density } \\
(\mathbf{d} ; \mathbf{g} / \mathbf{m l})\end{array}$ & $0.78974^{\mathrm{b}}$ & & \\
\hline $\begin{array}{c}\text { Strength of } \\
\text { Alcohol (z; \% v/v) }\end{array}$ & See Table 2 ${ }^{\mathrm{c}}$ \\
\hline
\end{tabular}

Data from:

${ }^{a}$ Gullberg [10]

${ }^{\mathrm{b}}$ Maskell et al. [5]

${ }^{\mathrm{c}}$ This Study 
Table 3: The proportion (as a percentage) that each variable of the Widmark equation contributes to estimating the uncertainty in $\mathrm{C}_{0}$ (the maximum theoretical $\mathrm{BAC}$ at the time the ethanol dose was administered) based on data from Tables 1 and 2.

\begin{tabular}{|c|c|c|c|c|c|c|c|c|}
\hline$\%$ ABV $(\% \mathbf{v} / \mathbf{v})$ & 3.4 & 4.9 & 5.5 & 5.6 & 7.9 & 9.4 & $\begin{array}{c}10 . \\
9\end{array}$ & $\begin{array}{c}12 . \\
4\end{array}$ \\
\hline Volume of Drink $(\mathbf{v} ; \mathrm{ml})$ & 0.2 & 0.3 & 0.3 & 0.3 & 0.3 & 0.4 & 0.4 & 0.4 \\
\hline Strength of Alcohol (z; \% v/v) & $\begin{array}{c}64 . \\
1\end{array}$ & $\begin{array}{c}46 . \\
3\end{array}$ & $\begin{array}{c}40 . \\
6\end{array}$ & $\begin{aligned} & 50 . \\
& 0\end{aligned}$ & $\begin{array}{ll}33 . \\
5\end{array}$ & $\begin{array}{c}26 . \\
2\end{array}$ & $\begin{array}{c}20 . \\
9\end{array}$ & $\begin{array}{c}17 . \\
0\end{array}$ \\
\hline Alcohol Density (d; g/ml) & 0.0 & 0.0 & 0.0 & 0.0 & 0.0 & 0.0 & 0.0 & 0.0 \\
\hline $\begin{array}{l}\text { Volume of distribution of ethanol } \\
\qquad(\mathrm{r} ; \mathrm{l} / \mathrm{kg})\end{array}$ & $\begin{array}{c}34 . \\
1\end{array}$ & $\begin{array}{c}51 . \\
1\end{array}$ & $\begin{array}{c}56 . \\
4\end{array}$ & $\begin{array}{l}47 . \\
5\end{array}$ & $\begin{array}{c}63 . \\
2\end{array}$ & $\begin{array}{c}70 . \\
1\end{array}$ & $\begin{array}{c}75 . \\
2\end{array}$ & $\begin{array}{c}78 . \\
9\end{array}$ \\
\hline Weight (kg) & 1.6 & 2.4 & 2.7 & 2.2 & 3.0 & 3.3 & 3.5 & 3.7 \\
\hline & & & n & & & & & \\
\hline Calculated $C_{o}(\mathrm{mg} / \mathbf{1 0 0 m l})$ & $\begin{array}{c}31 . \\
1\end{array}$ & $\begin{array}{c}44 . \\
9\end{array}$ & $\begin{array}{c}50 . \\
3\end{array}$ & $\begin{array}{c}51 . \\
3\end{array}$ & $\begin{array}{c}72 . \\
3\end{array}$ & $\begin{array}{c}86 . \\
1\end{array}$ & 100 & 114 \\
\hline SD & 4.9 & 5.8 & 6.2 & 6.9 & 8.4 & 9.5 & 11 & 12 \\
\hline$\% \mathrm{CV}$ & 16 & 13 & 12 & 13 & 12 & 11 & 11 & 10 \\
\hline
\end{tabular}


Highlights

- The results of Widmark calculations are subject to uncertainty of measurement

- No clear UK data on the uncertainty of labelled alcohol concentration in beer

- RMSE Variation of labelled ABV $\leq 5.5 \%$ is $\pm 0.43 \% \mathrm{v} / \mathrm{v}(\mathrm{n}=112)$

- RMSE Variation of labelled ABV $>5.5 \%$ is $\pm 0.53 \% \mathrm{v} / \mathrm{v} \quad(n=106)$

- The contribution of the uncertainty of declared $A B V$ is larger than previously thought 